\title{
A Comparison of Construction Cost Estimation Using Multiple Regression Analysis and Neural Network in Elementary School Project
}

\author{
Cho, Hong-Gyu ${ }^{1}$ Kim, Kyong-Gon ${ }^{1}$ Kim, Jang-Young ${ }^{2}$ Kim, Gwang-Hee ${ }^{3 *}$ \\ Graduate School, Kyonggi University, Yeongtong-Gu, Gyeonggi-do, 154-42, Korea ${ }^{1}$ \\ The fifth rank official, Gyeonggi Provincial office of Education, Jangan-Gu, Gyeonggi-do, 495, Korea ${ }^{2}$ \\ Dept. of Plant \& Architectural Engineering, Kyonggi University, Yeongtong-Gu, Gyeonggi-do, 154-42, Korea ${ }^{3}$
}

\section{Abstract}

In the early stages of a construction project, the most important thing is to predict construction costs in a rational way. For this reason, many studies have been performed on the estimation of construction costs for apartment housing and office buildings at early stage using artificial intelligence, statistics, and the like. In this study, cost data held by a provincial Office of Education on elementary schools constructed from 2004 to 2007 were used to compare the multiple regression model with an artificial neural network model. A total of 96 historical data were classified into 76 historical data for constructing models and 20 historical data for comparing the constructed regression model with the artificial neural network model. The results of an analysis of predicted construction costs were that the error rate of the artificial neural network model is lower than that of the multiple regression model.

Keywords : elementary school, construction cost estimation, multiple regression analysis, artificial neural networks

\section{Introduction}

The importance of predicting construction cost at the initial phase of a construction project has been emphasized, as it affects the decision-making of the owners[1]. But the prediction of construction cost is made after the basic design is completed at the initial phase of a construction project based on knowledge and experience that has previously been accumulated[2]. For this reason, the success of a construction project depends on an accurate prediction of the construction cost, and for this reason, many related studies have been conducted[3].

Traditionally, statistical models[4,5] including regression analysis models $[6,7,8]$, have mainly been

Received : October 15, 2012

Revision received : October 29, 2012

Accepted : October 30, 2012

* Corresponding author : Kim, Gwang-Hee

[Tel: 82-31-249-9757, E-mail: ghkim@kyonggi.ac.kr]

(c)2013 The Korea Institute of Building Construction, All rights reserved. used to predict construction cost; however, an artificial neural network, which is designed by imitating the human brain and is in wide use in all industries, has also been applied to the construction field, and the applicability of a neural network to the construction field has been studied[9,10]

In addition, there have been some studies in which the neural network was employed to improve the accuracy of prediction and overcome the restrictions of a regression analysis model in construction cost prediction[11,12,13,14]. In particular, it was found that for cost prediction, a neural network model was superior to a regression analysis model $[15,13,16,17]$.

Studies on construction cost prediction were conducted by applying either a regression analysis model[3] or an artificial neural network model $[18,19]$ to a school facility field. The previously mentioned comparison of the accuracy of prediction of the regression analysis model and 
the artificial neural network model was conducted for a commercial building and an apartment building. Although a comparison of the accuracy of construction cost estimation between a regression analysis model and an artificial neural network was conducted for a school facility, more detailed studies needed to be performed.

For this reason, a regression analysis model and an artificial neural network model were built for an elementary school of educational facilities to conduct an analysis of the accuracy of construction cost prediction at the initial phase of a project that would compare the two models in this study. The research findings are expected to provide the information needed to utilize an accurate prediction model for construction cost that takes the characteristics of a school facility into account, by considering the advantages and disadvantages of each model.

The scope of this study was limited to elementary schools, and the construction cost data of elementary schools built from 2004 to 2007 provided by Gyeonggi Educational Office were utilized. Utilizing the collected actual construction cost data, two construction cost prediction models were built: one based on the multiple regression analysis model and the other based on the artificial neural network model. Data not utilized in building the models was used as test data to compare the accuracy of the models.

To do this, SPSS 10.0 was used to build the multiple regression analysis model, and NeuroSolutions 6.0 by NeuroDimension was used to build the artificial neural network model. The scope of this research was limited to a comparison of the accuracy of the two models built.

This research was conducted as presented in Figure 1. In more specific terms, the research proceeded as follows:
First, literature review was performed by analyzing previous studies on regression analysis and artificial neural network;

Second, data on the actual construction cost for elementary schools built in the jurisdiction of Gyeonggi Educational Office from 2004 and 2007 was collected;

Third, based on the actual construction cost, input variables were selected, and the variables that were found to have an effect on construction cost were selected through a correlation analysis;

Fourth, utilizing the collected actual construction cost, the regression analysis model and the artificial neural network model were built;

Fifth, predicted construction cost was calculated for each model by applying the actual construction cost and test data to the models developed; and

Sixth, the accuracy of the construction cost prediction of the two models was compared.

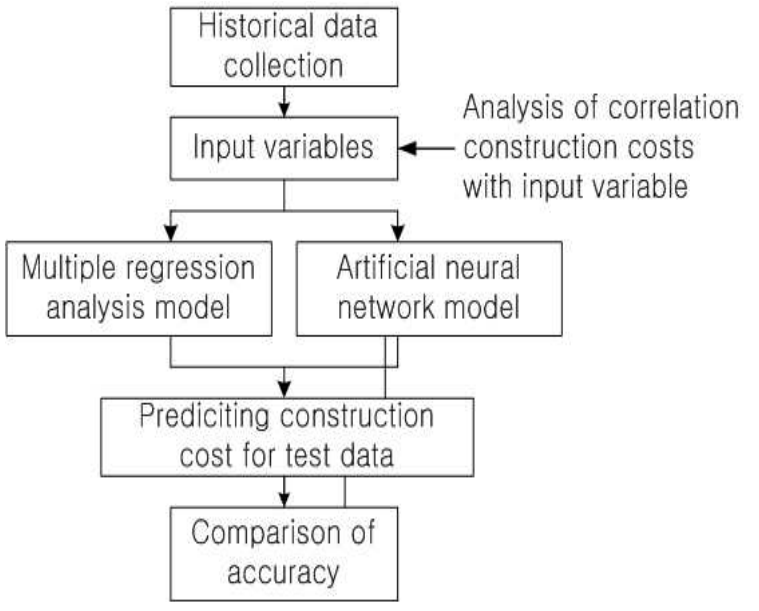

Figure 1. Research procedures

\section{Literature Review}

Studies on construction cost prediction for school facilities, through either the regression analysis or through the artificial neural network method, are indicated in Table 1. 
Table 1. Literature review on educational facility construction cost prediction model

\begin{tabular}{ccc}
\hline Author & Major research & Techniques \\
\hline $\begin{array}{c}\text { Kim et al. } \\
\text { [3] }\end{array}$ & $\begin{array}{c}\text { Construction cost estimating model } \\
\text { according to the spatial planning of } \\
\text { educational facilities was developed } \\
\text { using the historical data of } \\
\text { educational facilities BTL project at } \\
\text { the panning design stage } \\
\text { analysis } \\
\text { (RA) }\end{array}$ & \\
Kim and & An artificial neural network(ANN) & Artificial \\
Son & model for the construction estimate & neural \\
[18] & of the public educational facility at & network \\
& conceptual stage was proposed & (ANN) \\
Son et al. & A Construction cost estimation & RA \\
[19] & model for BTL educational facilities & $\&$ \\
& was developed using artificial & ANN \\
& neural network and regression & \\
& analysis & \\
\hline
\end{tabular}

As presented in Table 1, there have been some studies that were similar to this one, but the research conducted by Kim et al.[3] was about a BTL project for an educational facility ordered by Gyeonggi Educational Office, and the regression analysis was employed in the model building. In this study, the actual data was restricted to Build-Transfer-Lease (BTL) projects, and the construction cost was estimated based on classroom space and project size for all of the elementary, middle and high schools.

The research conducted by Kim and Son[18] was on a BTL project for an educational facility, and the artificial neural network model was employed. However, the construction duration was one of the input variables and construction cost index was applied to the actual construction cost, which is believed to have been an error; however, this study is differentiated as the accuracy of the artificial neural network model was the main subject of this research, rather than the building of an artificial neural network model.

In addition, there is the study done by Son et al.[19], which has the most in common with this study. In this study, the actual data of 14 BTL projects of elementary, middle and high schools were used to build the regression analysis model and the artificial neural network model, and then the prediction values of the two projects were compared. However, the actual data of 14 schools is believed to be insufficient to build a regression analysis model and an artificial neural network model.

In the previous studies, all the schools including elementary, middle and high schools were incorporated, but the actual data collected for this study consisted of elementary schools, which would help to reflect the unique characteristics of elementary schools that are different from those of middle and high schools, and the actual data of government projects and BTL projects was also collected, differentiating this from previous studies in which only the data of BTL projects was employed.

\subsection{Regression analysis}

According to the research performed by Kim[20] using a statistical method, studies related with construction cost estimation began in the 1980s in Korea, and one of the most representative construction cost estimation methods is regression analysis.

The regression analysis method is one of the representative statistical analysis methods to express changes of the target value in accordance with variables in a functional equation by making a function between a couple of parameters. Therefore, the regression analysis function is comprised of a dependent variable and one or more independent variables, and a multiple regression analysis having two or more independent variables can be expressed as Eq.(1)

$$
Y=a_{1} X_{1}+a_{2} X_{2}+\ldots+a_{n} X_{n}+C
$$


Here, $\mathrm{Y}$ is a dependent variable, $\mathrm{Xn}$ is an independent variable, and $\mathrm{C}$ is a constant.

The studies in Table 2 are on construction cost estimation using a statistical method.

\subsection{Artificial neural network (Artificial Neural Network)}

The neural network achieves artificial intelligence by modeling biological neurons in the human brain. That is, the biological neurons in the human brain and the relation between them are simplified, and they are modeled in a mathematical manner to implement an intelligent form as shown in the human brain, for utilization in engineering or other fields[21].

Table 2. Literatures review on construction cost prediction using statistics in Korea

\begin{tabular}{|c|c|}
\hline Author & Major research \\
\hline $\mathrm{Kim}[7]$ & $\begin{array}{l}\text { A construction cost estimating model for } \\
\text { apartment housing projects at the early stage } \\
\text { using regression analysis and standard index } \\
\text { of trades }\end{array}$ \\
\hline $\operatorname{Kim}[4]$ & $\begin{array}{l}\text { Combination cost estimating methodology } \\
\text { using Statistical methods and costing methods } \\
\text { for apartment housing project proposed }\end{array}$ \\
\hline Choi[8] & $\begin{array}{c}\text { Comparing unit cost estimation with regression } \\
\text { analysis technique in SRC type high rise } \\
\text { building }\end{array}$ \\
\hline $\begin{array}{c}\text { Ahn } \\
\text { and Kang[22] }\end{array}$ & $\begin{array}{c}\text { A cost estimating model using regression } \\
\text { analysis technique was developed for cost } \\
\text { estimation of apartment housing underground } \\
\text { parking lot projects in the early stage }\end{array}$ \\
\hline Lee et al.[23] & $\begin{array}{l}\text { Identifying problems in advance of the process } \\
\text { and the costs at the early stage by predicting } \\
\text { final costs using regression analysis }\end{array}$ \\
\hline Jung et al.[24] & $\begin{array}{l}\text { A regression model was presented for cost } \\
\text { estimation in the early stage according to } \\
\text { specific cost components of military facilities }\end{array}$ \\
\hline $\begin{array}{c}\text { Hyun } \\
\text { and Moon[25] }\end{array}$ & $\begin{array}{l}\text { A model was proposed for estimating the } \\
\text { range of construction and construction costs } \\
\text { at the project planning stage of public affairs } \\
\text { buildings using regression analysis }\end{array}$ \\
\hline Lee et al.[26] & $\begin{array}{l}\text { A conceptual regression analysis model was } \\
\text { proposed that establishes a new approach for } \\
\text { functional area cost estimation in the } \\
\text { schematic design phase. }\end{array}$ \\
\hline Kim et al.[3] & $\begin{array}{l}\text { According to the spatial planning of } \\
\text { educational facilities for BTL projects, cost } \\
\text { prediction regression models were proposed }\end{array}$ \\
\hline
\end{tabular}

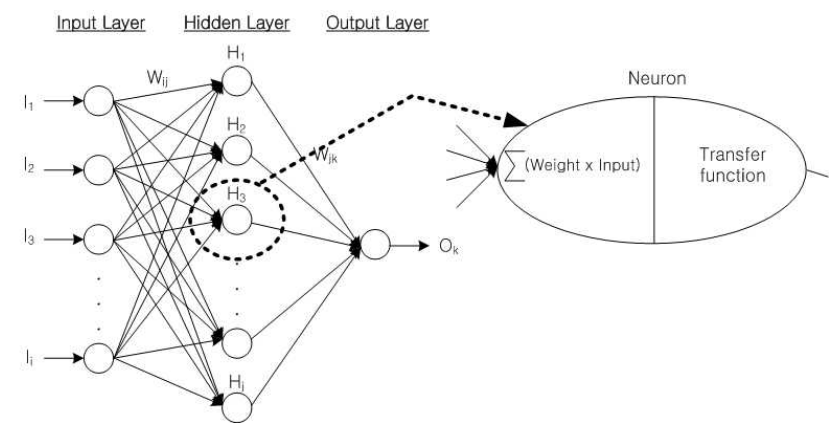

Figure 2. Artificial neural network structure

Table 3. Literatures review on artificial neural network cost prediction in korea

\begin{tabular}{cc}
\hline Author & Major research \\
\hline Kim and & Comparing neural network model with \\
Koo[14] & regression model in estimating costs of office \\
building
\end{tabular}

Park et al.[16] A neural network cost prediction model for apartment housing projects at the project planning stage was presented

Kim and Kang[28]

Kim and Kang[29]

Kim et al.[30]

Kim et al.[17] $\mathrm{Kim}$
and $\mathrm{Son}[18]$

Kim and $A h n[31]$

Son et al.[19]

Artificial neural network model for predicting BTL educational facilities constructed

As presented in Figure 2, the structure of the neural network consisted of input layer, hidden layer and output layer. More specifically, variables 
are input in the input layer, and the input variables are output to the output layer by multiplying the input variables with the weighted value in the hidden layer.

In general, there are one or more hidden layers between the input and output layers, and a transfer function is used to calculate the strength of the networking ties of the neurons (Wij or Wjk). As the transfer function, sigmoid function is mainly used [27], and here, momentum and bias are additional parameters.

The artificial neural network method is in wide use in diverse industries, and it is utilized for design, structure, construction, facility and environment in the construction industry as well. Table 3 lists the studies on construction cost estimation using artificial neural network method that have been conducted in Korea.

\section{Construction cost estimation model}

Table 4. Descriptive statistics of collected data

\begin{tabular}{cccc}
\hline Variables & Mean & Standard deviation & $\mathrm{N}$ \\
\hline $\begin{array}{c}\text { Historical costs } \\
(1,000 \mathrm{KWN})\end{array}$ & $9,224,483$ & $1,933,583$ & 96 \\
$\begin{array}{c}\text { No. of class } \\
\text { Building area }\left(\mathrm{m}^{2}\right)\end{array}$ & 31.29 & 7.149 & 96 \\
$\quad 2,623$ & 443 & 96 \\
Gross floor & 9,083 & 1,459 & 96 \\
$\quad$ area $\left(\mathrm{m}^{2}\right)$ & 4.67 & .619 & 96 \\
No. of upper FL. & .43 & .499 & 96 \\
No. of basement & $\mathrm{BTL}$ & National finance & Subtotal \\
\hline Financing type & 48 & 48 & 96 \\
\hline
\end{tabular}

The actual data collected are converted into the present value as of 2011 (the point of time for which construction cost index is presented) due to their time difference, and Table 5 indicates the converted coefficient to apply the construction cost index factor. The construction cost index announced by the Cost Center of Korea Institute of Construction Technology is based on 2005.

Table 5. Yearly cost index conversion factor

\begin{tabular}{ccccc}
\hline Year & 2004 & 2005 & 2006 & 2007 \\
\hline Conversion factor & 97.7 & 100.0 & 102.6 & 106.2 \\
\hline
\end{tabular}

Table 6. Input and output variables

\begin{tabular}{|c|c|c|c|}
\hline Variables & Type & $\begin{array}{c}\text { Regression } \\
\text { analysis }\end{array}$ & $\begin{array}{c}\text { Artificial neural } \\
\text { network }\end{array}$ \\
\hline Financing type & Nominal & \multirow{6}{*}{$\begin{array}{l}\text { Independent } \\
\text { variables }\end{array}$} & \multirow{6}{*}{ Input variables } \\
\hline Gross floor area & Numerical & & \\
\hline Building area & Numerical & & \\
\hline No. of class & Numerical & & \\
\hline No. of upper FL. & Numerical & & \\
\hline No. of basement & Numerical & & \\
\hline Construction costs & Numerical & ependent variable & $\begin{array}{c}\text { Output } \\
\text { variable }\end{array}$ \\
\hline
\end{tabular}

To build a regression analysis model and an artificial neural network model, the input variables that can be extracted from the actual collected data are shown in Table 6. The nominal variables of each variable were converted into dummy variables and then applied.

Table 7. Regression model summary

\begin{tabular}{|c|c|c|c|c|c|c|c|c|c|}
\hline \multirow[b]{2}{*}{ Model } & \multirow[b]{2}{*}{$\mathrm{R}$} & \multirow[b]{2}{*}{$R$ squares } & \multirow{2}{*}{$\begin{array}{l}\text { Adjusted R } \\
\text { square }\end{array}$} & \multirow[b]{2}{*}{ Std.error or the estimate } & \multicolumn{5}{|c|}{ Change statistics } \\
\hline & & & & & $\begin{array}{l}\text { R square } \\
\text { change }\end{array}$ & $F$ change & df1 & $\mathrm{d} 22$ & Sig. $f$ change \\
\hline 1 & $.933^{\mathrm{a}}$ & .871 & .860 & 723356.523203035800 & .871 & 77.816 & 6 & 69 & .000 \\
\hline 2 & $.000^{\mathrm{b}}$ & .000 & .000 & 1933583.224963900200 & -.871 & 77.816 & 6 & 69 & .000 \\
\hline
\end{tabular}

a. Predictors: (Constant), No. of basement, Building area, National finance, No. of upper FL, No. of class, Gross floor area

b. Predictor: (Constant) 
Table 8. Unstandardized coefficients

\begin{tabular}{|c|c|c|c|c|c|c|c|c|}
\hline & \multirow{2}{*}{ Model } & \multicolumn{2}{|c|}{ Unstandardized coefficients } & \multirow{2}{*}{$\frac{\text { Std. coefficients }}{\text { Beta }}$} & \multirow{2}{*}{$t$} & \multirow{2}{*}{ Sig. } & \multicolumn{2}{|c|}{$95.0 \%$ Confidence interval for $\mathrm{B}$} \\
\hline & & B & Std. error & & & & Lower bound & Upper bound \\
\hline \multirow{7}{*}{1} & Coefficients & -868655.114 & 996219.652 & & -.872 & .386 & -2856058.942 & 1118748.713 \\
\hline & National finanace & -1130493.530 & 235987.488 & -.294 & -4.790 & .000 & -1601275.687 & -659711.373 \\
\hline & No. of class & -67713.823 & 30358.212 & -.250 & -2.230 & .029 & -128276.799 & -7150.846 \\
\hline & Building area $\left(\mathrm{m}^{2}\right)$ & -21.833 & 296.797 & -.005 & -.074 & .942 & -613.927 & 570.262 \\
\hline & Gross floor area $\left(\mathrm{m}^{2}\right)$ & 1377.513 & 160.964 & 1.040 & 8.558 & .000 & 1056.399 & 1698.626 \\
\hline & No. of upper FL. & 51295.240 & 169761.015 & .016 & .302 & .763 & -287368.717 & 389959.198 \\
\hline & No. of basement & 189479.707 & 175756.973 & .049 & 1.078 & .285 & -161145.859 & 540105.274 \\
\hline
\end{tabular}

\subsection{Regression analysis model}

To build the regression analysis model, 20 data were randomly extracted from 96 data, and categorized for model validation, and the rest were applied in the model building. To build the construction cost prediction model for the elementary school facilities using regression analysis, the regression equation was derived through elimination according to the input method of independent variables. That is, after all the independent variables were considered for the estimation model, the independent variables that made a low contribution to explaining the dependent variables were eliminated, starting at the lowest, until there were no variables that failed to meet the contribution set in advance, and the final model was determined based on the remaining variables. Table 7 indicates the regression model summary, and $R^{2}$ of the explanatory variable was 0.860 , which gives a good explanation for the dependent variable.

The independent variable, BTL, was eliminated in the model, and significance of $\mathrm{F}$ change was 0.000, which is shown to be statistically significant.

Table 8 shows the unstandardized coefficients by variable derived from the regression analysis result, of which the significance probability utilized to verify significance of a regression coefficient was shown as between 0.000 and 0.942 . Here, the construction area, the number of aboveground floors, and the number of basement levels was shown to be 0.05, which is not statistically significant. The regression equation derived based on the results above is shown below.

$$
\begin{aligned}
Y= & -868,655.114-1,130,493.530^{*} X_{1} \\
& -67,713.823^{*} X_{2}-21.833^{*} X_{3}+1,377.513^{*} X_{4} \\
& +51,295.240^{*} X_{5}+189,479.707^{*} X_{6}
\end{aligned}
$$

$Y$ : construction cost(1,000KRW), $X_{1}$ : government, $X_{2}$ : number of classrooms, $X_{3}:$ :construction area,

$X_{4}$ : gross floor area, $X_{5}$ : ground floors, $X_{6}$ : basement floors

\subsection{Artificial neural network model}

To build an artificial neural network model, 96 data were categorized into 56 for learning, 20 for cross validation and 20 for validation, and then were applied. Table 9 indicates 4 multilayer perceptron artificial neural network models.

Of the artificial neural network models built, the model having the highest $r$ value (0.85) for validation data was selected to compare the validation result value of the regression analysis model.

\section{Model validation}

A regression analysis model and an artificial 
Table 9. Artificial neural network model summary

\begin{tabular}{|c|c|c|c|c|c|c|c|c|c|}
\hline \multirow{2}{*}{$\begin{array}{c}\text { Model } \\
\text { (Multilayer perceptron) }\end{array}$} & \multicolumn{3}{|c|}{ Training data } & \multicolumn{3}{|c|}{ Cross validation data } & \multicolumn{3}{|c|}{ Test data } \\
\hline & MSE & $r$ & MAE & MSE & $r$ & MAE & MSE & $r$ & MAE \\
\hline MLP-model 1 & $7.48 \mathrm{E}+11$ & 0.921788 & 675498 & $6.91 \mathrm{E}+11$ & 0.867524 & 714547.4 & $3.66 \mathrm{E}+12$ & 0.421716 & 1334270 \\
\hline MLP-model 2 & $4.48 \mathrm{E}+11$ & 0.947325 & 539797.1 & $5.53 \mathrm{E}+11$ & 0.863282 & 627352.6 & $1.16 \mathrm{E}+12$ & 0.795372 & 906974.5 \\
\hline MLP-model 3 & $8.02 \mathrm{E}+11$ & 0.91314 & 768365 & $4.74 \mathrm{E}+11$ & 0.860463 & 573638.2 & $8.53 \mathrm{E}+11$ & 0.846942 & 725164.2 \\
\hline MLP-model 4 & $1.1 \mathrm{E}+12$ & 0.868116 & 870900.5 & $5.67 \mathrm{E}+11$ & 0.82544 & 576731.2 & $9.23 E+11$ & 0.851785 & 778748.5 \\
\hline
\end{tabular}

MSE(Mean Squared Error), MAE(Mean Absolute Error)

neural network model were built for construction cost estimation of elementary schools, and the predicted data were compared with the validation data. 20 data for validation were not used in either the regression analysis model or in the artificial neural network model.

As presented in Figure 4 and Table 12, the average error rate and the standard distribution of the regression analysis model stood at $10.02 \%$ and 6.30, respectively, while the average error rate and the standard distribution of the artificial neural network model stood at 7.99\% and 5.51, respectively, based on which it was revealed that the prediction of the artificial neural network is superior to that of the regression analysis model. This is similar to the results of previous studies on apartment buildings or commercial buildings.

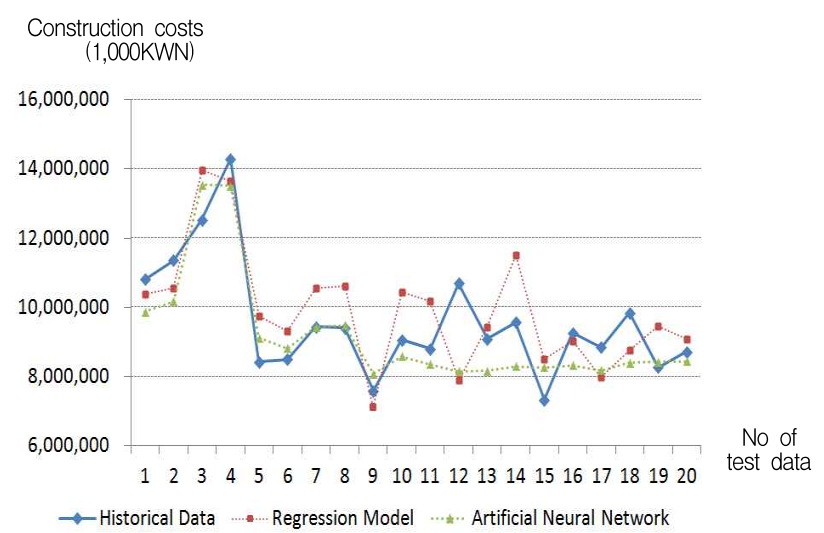

Figure 3. Historical construction cost and prediction construction cost
Table 10. Verification results of regression model and artificial neural network

\begin{tabular}{cccccc}
\hline No. & $\begin{array}{c}\text { Construction } \\
\text { costs } \\
(1,000 \text { KWN })\end{array}$ & Regression & model & \multicolumn{2}{c}{$\begin{array}{c}\text { Artificial } \\
\text { network }\end{array}$} \\
& model \\
\hline No. & $\begin{array}{c}\text { Construction } \\
\text { costs } \\
(1,000 K W N)\end{array}$ & $\begin{array}{c}\text { Predicted } \\
\text { costs }\end{array}$ & $\begin{array}{c}\text { Error } \\
\text { rate } \\
(\%)\end{array}$ & $\begin{array}{c}\text { Predicted } \\
\text { costs }\end{array}$ & $\begin{array}{c}\text { Error rate } \\
(\%)\end{array}$ \\
\hline 1 & $10,811,577$ & $10,376,010$ & 7.16 & $9,869,794$ & 8.71 \\
2 & $11,354,400$ & $10,550,469$ & 11.60 & $10,176,940$ & 10.37 \\
3 & $12,532,827$ & $13,964,637$ & 8.98 & $13,545,228$ & 8.08 \\
4 & $14,284,094$ & $13,658,223$ & 7.87 & $13,510,920$ & 5.41 \\
5 & $8,426,860$ & $9,737,547$ & 11.54 & $9,121,725$ & 8.25 \\
6 & $8,499,175$ & $9,322,509$ & 3.48 & $8,820,447$ & 3.78 \\
7 & $9,433,067$ & $10,545,610$ & 6.86 & $9,434,902$ & 0.02 \\
8 & $9,403,722$ & $10,623,473$ & 8.02 & $9,482,945$ & 0.84 \\
9 & $7,585,668$ & $7,120,055$ & 10.69 & $8,074,910$ & 6.45 \\
10 & $9,053,443$ & $10,442,971$ & 9.68 & $8,580,459$ & 5.22 \\
11 & $8,796,718$ & $10,188,085$ & 12.27 & $8,353,673$ & 5.04 \\
12 & $10,696,480$ & $7,890,065$ & 30.43 & $8,155,366$ & 23.76 \\
13 & $9,094,468$ & $9,438,311$ & 0.07 & $8,171,393$ & 10.15 \\
14 & $9,571,712$ & $11,518,169$ & 15.65 & $8,299,676$ & 13.29 \\
15 & $7,321,599$ & $8,491,793$ & 8.85 & $8,263,568$ & 12.87 \\
16 & $9,258,589$ & $9,010,407$ & 7.48 & $8,326,513$ & 10.07 \\
17 & $8,842,225$ & $7,988,362$ & 13.03 & $8,172,337$ & 7.58 \\
18 & $9,841,576$ & $8,756,305$ & 16.07 & $8,401,101$ & 14.64 \\
19 & $8,268,071$ & $9,466,555$ & 9.20 & $8,430,890$ & 1.97 \\
20 & $8,720,310$ & $9,084,898$ & 1.53 & $8,436,074$ & 3.26 \\
& Mean(\%) & & 10.02 & & 7.99 \\
\hline & Standard deviation & 6.30 & & 5.51 \\
\hline
\end{tabular}

\section{Conclusion}

To compare the accuracy of construction cost prediction methods, the actual construction cost data of 96 elementary schools built between 2004 and 2007 provided by Gyeonggi Educational Office were utilized, and the accuracy of the cost 
estimation was compared by building the regression analysis model and the artificial neural network model.

By comparing the estimated values of the two models, the artificial neural network model was found to be superior in terms of average error rate and standard distribution. Therefore, the result was believed to be similar to the results found in previous studies on construction cost estimation for apartment buildings, and it is more effective in terms of accuracy to use the artificial neural network model for construction cost estimation of school facilities, including elementary schools, with project information at least.

However, the model needs to be more generalized through further studies, as the results can differ due to various factors, including difficulties in model building and the number of data.

\section{References}

1. Park MS, Seong KH, Lee HS, Ji SH Kim SY. Schematic Cost Estimation Method using Case-Based Reasoning / Focusing on Determining Attribute Weight. Korean Journal of Construction Engineering and Management. 2010 Jul;11(4):22-31.

2. An SH, Yoon JE, Kang KI. A Study on the Assessment Model of Preliminary Cost Estimates Using Discriminant Analysis. Journal of the Architectural Institute of Korea (Structure and Construction). 2005 Sep;21(9):169-77.

3. Kim JW, Lee BR, Kim JH, Kim JJ. A Study on Construction Cost Estimation Model According to the Spatial Planning of Educational Facilities using Regression Analysis / For the BTL Project in the Gyeonggi-do Region. Journal of the Architectural Institute of Korea (Planning and design). 2011 Oct;27(10):103-10.

4. Kim SK. A study on the hybrid cost model of apartment housing projects in the early design stage [Dissertation]. [Seoul (Korea)]: Seoul National University; 1992. 214 p.

5. Singh S. Cost estimation of structures in commercial buildings. New York (NY): Macmillan; 1994. 185 p.

6. Singh S. Cost model for reinforced concrete beam and slab structures in building. Journal of Construction Engineering and Management. 1990 Mar;116(1):54-67.

7. Kim KD. A Study on the Development of the Cost Model for the Domestic Apartment House [Dissertation]. [Seoul (Korea)]: Seoul National University; 1991. 194 p.

8. Choi IS, Hong SH, Son CB, Ko SC. A Study on the Prediction Model of Construction Cost in High-Rise Office Building of SRC Type. Journal of the Architectural Institute of Korea (Structure and Construction). 1999 Jul;15(7):143-51.

9. Moselhi O. Hegazy T. Fazio P. Neural networks as tools in construction. Journal of Construction Engineering and Management. 1991 Dec;117(4):606-25.

10. Boussabaine $\mathrm{AH}$. The use of artificial neural networks in construction management: a review. Construction Management and Economics. 1996 Oct;14(1):427-36.

11. Mckim R. Neural network application to cost engineering. Cost Engineering. 1993 Jul;35(7):31-5.

12. Yeh IC. Quantity estimating of building with logarithm-neuron networks. Journal of Construction Engineering and Management. 1998 Oct;124(5):374-80

13. Bode J. Neural networks for cost estimating: simulation and pilot application. International Journal of Production Research. 2000 Nov;38(6):123-54.

14. Kim SK, Koo IW. A Neural Network Cost Model for Office Buildings. Journal of the Architectural Institute of Korea 2000 Sep;16(9):59-67.

15. Garza J, Rouhana K. Neural network versus parameter-based application. Cost Engineering. 1995 Feb;37(2):14-8.

16. Park WY, Cha JH, Kang KI, A Neural Network Cost Model for Apartment Housing Projects in the Initial Stage, Journal of the Architectural Institute of Korea, 2002 July;18(7):155-62.

17. Kim GH, An SH, Cho HK. Comparison of the Accuracy between Cost Prediction Models based on Neural Network and Genetic Algorithm / Focused on Apartment Housing Project Cost. Journal of the Architectural Institute of Korea. 2006 Mar;23(3):111-8.

18. Kim CY, Son JH. A Study on the Model of Artificial Neural Network forConstruction Cost Estimation of Educational Facilities at Conceptual Stage. Korean Journal of Construction Engineering and Management. 2006 Aug;7(4):91-9.

19. Son JH, Kim SK, Kim JO. A Study on the Analysis and Estimation of the Construction Cost by Using Artificial 
Neural Network in the BTL Projects for Educational Facilities. Journal of Architectural Institute of Korea. 2008 Jul:24(6):135-42.

20. Kim GH. Construction Cost Prediction System Based on Artificial Intelligence at the Project Planning Stage [Dissertation]. Seoul (Korea): Korea University; 2004. 230 p.

21. Lim YD, Lee SB. Fuzzy · Sin'gyeongmang · Yugeonjinhwa [Fuzzy $\cdot$ Neural network - Genetic evolution]. Seoul (Korea): Insol Media; 1999. 272 p. Korean.

22. An SH, Kang KI. A Study on the Cost Model of Underground Parking Lot of Apartment Housing Projects in the Early Stage. Journal of the Architectural Institute of Korea (Structure and Construction). 2005 May;21(5):135-42.

23. Lee YM, Lee MH, Lee HK. The Study on the System to Estimate the Cost by Using Regression in the Early Stage of the Project. Proceeding of Korea Institute of Construction Engineering and Management; 2006 Nov 11; Suwon, Korea. Seoul (Korea): Korea Institute of Construction Engineering and Management; 2006. p. 274-7.

24. Jung MJ, Lee HS, Park MS. Cost Estimating for Military Facilities at Early Construction Stage Focusing on Military Barracks. Proceeding of Korea Institute of Construction Engineering and Management; 2009 Nov 19-20; Daejon, Korea. Seoul (Korea): Korean Institute of Construction Engineering and Management; 2009. p. 195-8.

25. Hyun CT, Moon HS. Model for Predicting Cost and Cost Range of the Public Office Building at the Planning Phase. Journal of the Architectural Institute of Korea (Structure and Construction). 2010 Jun;26(6):139-48.

26. Lee HS, Jung M, Park M, Son BS. Cost Estimating for Public Facilities at Early Stage Using Functional Area Cost Focusing on Army Barracks. Korean Journal of Construction Engineering and Management. 2010 Nov;11(6):3-13.

27. Hegazy T, Moselhi O, Fazio P. Developing practical neural network applications using back-propagation. Computer-Aided Civil and Infrastructure Engineering. 1994 Mar;9(2):145-59.

28. Kim GH, Kang KI. A Study on Model of Neural Networks Training by Genetic Algorithms for Predicting Cost Estimates of Apartment Projects at the Early Project Stage. Journal of the Architectural Institute of Korea. 2003 Oct;19(10):133-42.

29. Kim GH, Kang KI. A Study on Predicting Cost Estimation of Apartment Building Using Neural Network's Architecture
Optimized by Genetic Algorithms. Journal of the Architectural Institute of Korea. 2004 Feb;20(2):81-8.

30. Kim GH, Kim SY, Kang KI. Comparing Accuracy of Prediction Cost Estimation Using Case-Based Reasoning and Neural Networks. Journal of the Architectural Institute of Korea. 2004 May;20(5):93-102.

31. Kim GH, An SH. A Study on the Correlation between Selection Methods of Input Variables and Number of Data in Estimation Accuracy / Cost Estimation using Neural Networks in Apartment Housing Projects. Journal of the Architectural Institute of Korea. 2007 Feb;23(4):129-37. 